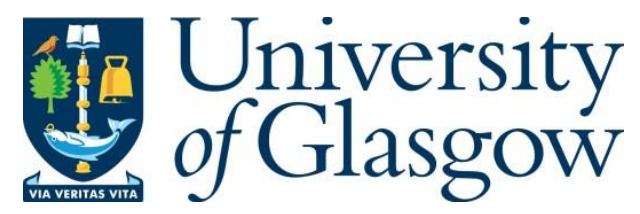

Kotzur, M., McCowan, C., Macdonald, S., Wyke, S., Gatting, L., Campbell, C., Weller, D., Crighton, E., Steele, R. J.C. and Robb, K. A. (2019) Why colorectal screening fails to achieve the uptake rates of breast and cervical cancer screening: a comparative qualitative study. BMJ Quality and Safety, (doi:10.1136/bmjqs-2019-009998).

There may be differences between this version and the published version. You are advised to consult the publisher's version if you wish to cite from it.

http://eprints.gla.ac.uk/202989/

Deposited on: 14 November 2019

Enlighten - Research publications by members of the University of Glasgow http://eprints.gla.ac.uk 
Why colorectal screening fails to achieve the uptake rates of breast and cervical cancer screening: a comparative qualitative study

Marie Kotzur (0000-0001-6921-5075), Colin McCowan (0000-0002-9466-833X), Sara

Macdonald (0000-0002-5380-6943), Sally Wyke (0000-0002-7509-8247), Lauren Gatting (0000-0003-3693-2013), Christine Campbell (0000-0003-4868-0554), David Weller (00000002-8112-718X), Emilia Crighton (0000-0003-2268-4442), Robert Steele (0000-0003-42486785), Kathryn Robb (0000-0002-1672-0411)

Marie Kotzur

Research Associate, Institute of Health and Wellbeing, University of Glasgow, Glasgow G120XH, UK

\section{Colin McCowan}

Professor in Health Data Science, School of Medicine, University of St Andrews, St Andrews KY16 9TF, UK

\section{Sara Macdonald}

Senior Lecturer, Institute of Health and Wellbeing, University Of Glasgow, Glasgow G12 9LX, UK

\section{Sally Wyke}

Interdisciplinary Research Professor, Institute of Health and Wellbeing, University Of

Glasgow, Glasgow G12 8RS, UK

Lauren Gatting

PhD student, Institute of Health and Wellbeing, University Of Glasgow, Glasgow G12 0XH, UK

\section{Christine Campbell}

Reader, Usher Institute, University of Edinburgh, Edinburgh EH8 9AG, UK

\section{David Weller}

James Mackenzie Professor of General Practice, Usher Institute, University of Edinburgh, Edinburgh EH8 9AG, UK

\section{Emilia Crighton}

Head of Health Services, NHS Greater Glasgow and Clyde, Gartnavel Royal Hospital, Glasgow G120XH, UK

\section{Robert Steele}

Senior Research Professor, School of Medicine, University of Dundee, Dundee DD14HN, UK Kathryn Robb 
37 Correspondence concerning this article should be addressed to Kathryn Robb, Institute of 38 Health and Wellbeing, University of Glasgow, Admin building, $1^{\text {st }}$ Floor, 1055 Great Western 39 Road, Glasgow G12 0XH. Email: Katie.Robb@glasgow.ac.uk

40

41 Word count: 4418

42 
Background: In Scotland, the uptake of clinic-based breast (72\%) and cervical (73\%) screening is higher than home-based colorectal screening ( $60 \%)$. To inform new approaches to increase uptake of colorectal screening, we compared the perceptions of colorectal screening among women with different screening histories.

Method: We purposively sampled women with different screening histories to invite to semistructured interviews: i) participated in all; ii) participated in breast and cervical but not colorectal ('colorectal-specific non-participants'); iii) participated in none. To identify the sample we linked the data for all women eligible for all three screening programmes in Glasgow, Scotland (aged 51-64 years; $n=68,324)$. Interviews covered perceptions of cancer, screening, and screening decisions. Framework Method was used for analysis.

Results: Of the 2,924 women invited, 86 expressed an interest, and 59 were interviewed. The three groups' perceptions differed, with the colorectal-specific non-participants expressing that: i) treatment for colorectal cancer is more severe than for breast or cervical cancer; ii) colorectal symptoms are easier to self-detect than breast or cervical symptoms; iii) they worried about completing the test incorrectly; and iv) the colorectal test could be more easily delayed or forgotten than breast or cervical screening.

Conclusions: Our comparative approach suggested targets for future interventions to increase colorectal screening uptake including: i) reducing fear of colorectal cancer treatments; ii) increasing awareness that screening is for the asymptomatic; iii) increasing confidence to self-complete the test; and iv) providing a suggested deadline and/or additional reminders. 


\section{BACKGROUND}

67 Colorectal cancer (CRC) is the second leading cause of cancer death worldwide.[1] CRC

screening by faecal occult blood test (FOBt) can reduce deaths.[2] In Scotland, since 2007, people aged 50-74 have been mailed a self-complete FOBt every two years as part of the Scottish Bowel Screening Programme. The FOBt requires people to collect two samples from each of three separate bowel motions and to mail their completed kit for processing. Women in Scotland are also invited to attend a pre-arranged appointment for breast screening using mammography and to make an appointment for cervical screening using the Pap smear (Table 1). All three screening tests are offered at no cost to participants through the National Health Service. Uptake of screening is $77 \%$ for cervical, $72 \%$ for breast but only $59 \%$ for colorectal among women aged 50 and over.[3-5] Screening uptake rates show similar patterns in Australia and the US with uptake of CRC screening lagging behind the participation rates of breast and cervical screening.[6, 7]

Table 1

Invitation procedures in the Scottish cancer screening programmes

\begin{tabular}{|c|c|c|c|}
\hline & \multicolumn{3}{|c|}{ Screening programme } \\
\hline & $\begin{array}{l}\text { Breast screening by } \\
\text { mammography }\end{array}$ & $\begin{array}{l}\text { Cervical screening by } \\
\text { smear test }\end{array}$ & $\begin{array}{l}\text { CRC screening by faecal occult } \\
\text { blood test }\end{array}$ \\
\hline $\begin{array}{l}\text { Pre- } \\
\text { notification }\end{array}$ & None & None & 2 weeks prior to invitation ${ }^{a}$ \\
\hline $\begin{array}{l}\text { Invitation } \\
\text { (mailed) }\end{array}$ & $\begin{array}{l}\text { Within } 3 \text { years after } 50^{\text {th }} \\
\text { birthday } \\
\text { Until } 70^{\text {th }} \text { birthday } \\
\text { After } 70^{\text {th }} \text { birthday on } \\
\text { request }\end{array}$ & $\begin{array}{l}\text { Before June } 2016 \text { : } \\
\text { After } 20^{\text {th }} \text { birthday } \\
\text { Until } 60^{\text {th }} \text { birthday } \\
\text { From June } 2016 \text { : } \\
\text { After } 25^{\text {th }} \text { birthday } \\
\text { Until } 65^{\text {th }} \text { birthday }\end{array}$ & $\begin{array}{l}\text { From } 50^{\text {th }} \text { birthday } \\
\text { Until } 75^{\text {th }} \text { birthday } \\
\text { After } 75^{\text {th }} \text { birthday on request }\end{array}$ \\
\hline $\begin{array}{l}\text { Reminder } \\
\text { (mailed) }\end{array}$ & $\begin{array}{l}\text { Reminder at } 3 \text { days } \\
\text { following non-attendance }\end{array}$ & $\begin{array}{l}\text { Reminders at } 3 \text { months } \\
\text { and at } 6 \text { months after } \\
\text { the invitation }\end{array}$ & $\begin{array}{l}\text { Reminder at } 6 \text { weeks after the } \\
\text { invitation }\end{array}$ \\
\hline $\begin{array}{l}\text { Screening } \\
\text { interval }\end{array}$ & Every 3 years & $\begin{array}{l}\text { Aged 25-49: every } 3 \\
\text { years } \\
\text { Aged 50-64: every } 5 \\
\text { years }\end{array}$ & Every 2 years \\
\hline
\end{tabular}

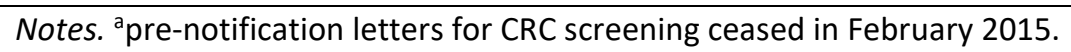


Reasons for the low uptake of CRC screening include lack of awareness, feeling healthy, negative views of cancer (fear, fatalism), negative attitudes towards colorectal tests, lack of motivation including other health concerns, and cultural, gender and socioeconomic influences.[8-11] Many of these potential barriers also apply to breast and cervical screening,[12] so it is unclear why CRC screening uptake should remain considerably lower. There have been few comparisons of barriers across these three screening modalities. $[13,14]$ We identified only one study that directly compared barriers to breast, cervical and CRC screening uptake among women eligible for all three tests.[15] This British self-report survey of 890 women found that among those who participated in breast and cervical but not colorectal programmes, $23 \%$ reported not liking the idea of CRC screening test and $18 \%$ said they 'haven't got round to it, but intend to take part' as explanations for non-participation in CRC screening.[15] These explanations relate to both motivational influences such as dislike of the test, and volitional aspects of 'not getting round to it',[16] the latter being particularly salient for CRC screening which, unlike breast and cervical screening, is self-completed at home. Our study adds to those data in three main respects. Firstly, rather than using selfreported data of screening history, we linked cancer screening uptake data for the breast, cervical and CRC screening programmes for the complete population of Glasgow, Scotlanda socioeconomically diverse region with low overall screening uptake. Using this linked dataset, we identified women with three different screening histories: i) participated in all programmes; ii) participated in breast and cervical but not colorectal programmes; and iii) did not participate in any programme. Secondly, we invited women across these three groups to an individual in-depth interview, rather than a questionnaire, to provide the opportunity for women to speak at length about their perceptions and experiences of cancer screening. 
Thirdly, we organised our findings using the route MAP approach which is a useful tool to summarise the central tenets of multiple models of behaviour change [17]. The MAP describes three routes to behaviour: i) Motivation — strategies that increase and sustain motivation (e.g. information about the behaviour, reassurance); Action-on-motivation-strategies that strengthen and elaborate skills needed to translate motivations into action (e.g. setting behavioural goals, action and coping planning); and Prompted or cued routes - strategies that support behaviour change without the continuous cognitive effort required by the Motivation and Action-on-motivation routes (e.g. prompt, change the environment to facilitate the target behaviour). The MAP approach therefore provides a theoretically informed framework to identify targets for intervention.

The present study was designed to 1 ) identify why women (who are eligible for all three types of screening) choose to participate in breast and cervical screening but not CRC screening, and 2) gain insight into how CRC screening uptake can achieve the uptake rates of breast and cervical screening.

\section{METHODS}

\section{Participants and recruitment strategy}

This study was conducted alongside a quantitative study exploring cancer screening uptake among women living in Glasgow, Scotland. Data on screening participation for the breast, cervical and CRC screening programmes were linked for all women aged 20 to $74(n=430,591)$ who were registered with NHS Greater Glasgow and Clyde Health Board and invited to screening during the period 2009 to 2013 . This linked dataset was used as a sampling frame for the present study to select women who were eligible for breast, cervical and CRC screening 

socioeconomic position we aimed to interview women in each of six groups (Table 2).

Table 2

Sampling frame

\begin{tabular}{|c|c|c|c|}
\hline & \multicolumn{3}{|c|}{ Screening behaviour } \\
\hline & $\begin{array}{l}\text { Screening participants } \\
\text { (screened for breast, } \\
\text { cervical and CRC) }\end{array}$ & $\begin{array}{l}\text { CRC specific non-participants } \\
\text { (screened for breast and } \\
\text { cervical, but not CRC) }\end{array}$ & $\begin{array}{c}\text { Non-participants } \\
\text { (not screened for breast, } \\
\text { cervical or CRC) }\end{array}$ \\
\hline \multicolumn{4}{|l|}{ Living in } \\
\hline $\begin{array}{l}\text { Most } \\
\text { socioeconomically } \\
\text { deprived areas (SIMD } \\
\text { quintiles 1-2) }\end{array}$ & $\begin{array}{c}\text { Invited = } 119 \\
\text { Expressed interest = } 13 \\
\text { Interviewed }=11 \\
\text { Response rate }=10 \cdot 92 \%\end{array}$ & $\begin{array}{c}\text { Invited }=244 \\
\text { Expressed interest }=13 \\
\text { Interviewed }=9 \\
\text { Response rate }=5 \cdot 33 \%\end{array}$ & $\begin{array}{c}\text { Invited }=1,611 \\
\text { Expressed interest }=14 \\
\text { Interviewed }=10 \\
\text { Response rate }=0.87 \%\end{array}$ \\
\hline $\begin{array}{l}\text { Least } \\
\text { socioeconomically } \\
\text { deprived areas (SIMD } \\
\text { quintiles 4-5) }\end{array}$ & $\begin{array}{c}\text { Invited }=20 \\
\text { Expressed interest }=11 \\
\text { Interviewed }=10 \\
\text { Response rate }=55 \cdot 00 \%\end{array}$ & $\begin{array}{c}\text { Invited }=159 \\
\text { Expressed interest }=14 \\
\text { Interviewed }=9 \\
\text { Response rate }=8.81 \%\end{array}$ & $\begin{array}{c}\text { Invited }=771 \\
\text { Expressed interest }=13 \\
\text { Interviewed }=10 \\
\text { Response rate }=1.69 \%\end{array}$ \\
\hline
\end{tabular}

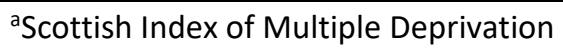

127

Purposive sampling was used to randomly identify and invite to interview women with three different screening histories: i) women who participated in all programmes (screening participants); ii) women who participated in breast and cervical but not colorectal programmes (CRC-specific non-participants); and iii) women who participated in none (nonparticipants). The sample was also stratified to obtain a mix of women from areas of high or low socioeconomic deprivation (Table 2). Socioeconomic deprivation was indexed by the Scottish Index of Multiple Deprivation (SIMD), an area-based measure of multiple deprivation linked to each individual's home address.[18] The aim was to obtain approximately ten interviews across the six stratified groups (Table 2). It was anticipated that recruiting nonparticipants and women living in deprived areas would be more challenging.[19] To ensure we achieved equal numbers of participants across the six groups we significantly oversampled non-participants and women living in deprived areas. In total, 2,924 women were invited (Table 2). 
142 The research team provided the Glasgow Clinical Research Facility with the sampling frame to identify 2,924 women of the 68,324 eligible for all three screening tests to be sent invitation packs. Invitation packs contained a letter inviting women to participate in a study exploring views on bowel, breast and cervical cancer screening, a participant information sheet, and a response form with options to indicate interest by email, phone or using a pre-paid envelope enclosed. Participants were offered $£ 20$ for participation and to cover the cost of refreshments and travel to the interview. Only women responding to the invitation pack were subsequently identified to the research team. Ethical approval was obtained from the NHS Health Research Authority (NRES Committee North West - Liverpool Central, REC reference: 4/NW/1300).

\section{Interview procedure and materials}

The interviewer (MK) met with respondents at locations of their choice: home $(n=35)$, the University Of Glasgow $(n=15)$, work $(n=3)$, community centre $(n=5)$, a parish house $(n=1)$. MK had spoken to the participants by phone prior to the interview, but had no relationship with them otherwise. MK is female and had previous experience of conducting interviews and focus groups with women about cancer screening. All participants provided informed consent before the semi-structured interview started. The interview followed a topic guide and began with an open question, 'What comes to mind when you think about cancer?' This was followed in turn with questions on what comes to mind in relation to bowel, breast and cervical cancers. The next question asked how they felt about their chances of developing breast, cervical or CRC. Participants were then asked for their thoughts and feelings about cancer screening. The interviewer asked, 'What comes to mind when you think about bowel cancer 
screening?' with supplementary questions on their understanding of what the test involves and the purpose. This was followed by the same questions in relation to breast and cervical screening. Finally, participants were shown example invitation letters and leaflets and were asked how they felt when they received these and how they decided what to do next. The interviews took place between November 2015 and April 2016, were an average length of 43 minutes, audio recorded and transcribed verbatim.

\section{Analysis}

172 The transcripts were analysed using the Framework Method, which takes a matrix based analytic approach to facilitate rigorous and transparent data management.[20] This approach permitted comparisons of accounts between women with different screening histories and living in different socioeconomic circumstances.

MK, KR and SM read and re-read the data. A mind-mapping process was developed based on the one-sheet-of-paper method.[21] From these mind maps, MK identified themes as the basis of the framework matrix. The themes were organised into the three MAP routes: motivation; action-on-motivation; and prompts.[17] As described by Ritchie and colleagues,[20] the framework matrix was organised in a MS Excel spreadsheet containing one theme per worksheet with sub-themes in the columns. The rows contained individual participants, grouped by screening history and socioeconomic status. The themes and subthemes within the framework matrix were discussed within the research team. Two researchers ( $M K$ and $L G$ ) coded the transcript in full and populated the framework matrix with relevant data extracts. They discussed comments and queries using web-based collaboration software (Trello), thus creating an audit trail. MK summarised each theme by comparing 
status) and noting representative data extracts. KR reviewed and discussed the summaries with MK to ensure consistency with the data.

\section{RESULTS}

\section{Sample characteristics}

192 Of the 2,924 women sent an invitation to participate; 2,629 did not respond, 129 declined, 76 invitations were returned undelivered, four women had died, and 86 expressed an interest in being interviewed of which four were excluded (due to becoming uncontactable, residing primarily outside the UK, or having a stoma). In total, 61 interviews were scheduled and 59 women were interviewed.

Response rates varied considerably across the six groups; $55 \%$ of people who had participated in all three programmes, and who lived in the least deprived areas agreed to be interviewed, whereas only $0.9 \%$ of people who had participated in none of the programmes and lived in the most deprived areas agreed to be interviewed (Table 2). The respondents' age ranged from 51 to 64 years. The respondents' views varied most commonly by screening participation history (screening participants, CRC-specific non-participants, non-participants), which formed our main comparison category. Comparisons by socioeconomic deprivation did not show clear differences in respondents' views but are highlighted where differences were found.

The results were organised into the three routes of behaviour change described by the MAP approach: motivational challenges to CRC screening; action-on-motivation challenges to CRC screening; and prompts to CRC screening.[17, 22]. The results are summarised in Table 3. 
Summary of results identifying unique challenges to colorectal cancer screening in comparison to breast and cervical screening

\begin{tabular}{|c|c|c|c|}
\hline & $\begin{array}{l}\text { Screening participants } \\
\text { (screened for breast, cervical and CRC) }\end{array}$ & $\begin{array}{c}\text { Screening behaviour } \\
\text { CRC specific non-participants } \\
\text { (screened for breast and cervical, but not CRC) }\end{array}$ & $\begin{array}{c}\text { Non-participants } \\
\text { (not screened for breast, cervical or CRC) }\end{array}$ \\
\hline \multicolumn{4}{|c|}{ Motivational challenges to colorectal screening } \\
\hline Treatment beliefs & $\begin{array}{l}\text { Less negative view of treatment than in other two } \\
\text { groups }\end{array}$ & $\begin{array}{l}\text { CRC treatment perceived as more severe than } \\
\text { breast or cervical }\end{array}$ & Treatment most threatening aspect of cancer \\
\hline $\begin{array}{l}\text { Beliefs about the value } \\
\text { of screening }\end{array}$ & Valued screening & $\begin{array}{l}\text { Some questioned value of CRC screening and } \\
\text { self-sampling reduced credibility }\end{array}$ & $\begin{array}{l}\text { Questioned value as intolerable cancer } \\
\text { treatment would still be necessary }\end{array}$ \\
\hline $\begin{array}{l}\text { Disgust and } \\
\text { embarrassment }\end{array}$ & Acknowledged but overcome & $\begin{array}{l}\text { Frequently discussed as barriers, avoided } \\
\text { talking about CRC screening with others }\end{array}$ & Frequently discussed as barriers \\
\hline Symptom beliefs & $\begin{array}{l}\text { Acknowledged screening is for asymptomatic as } \\
\text { more treatable at earlier stage of diagnosis }\end{array}$ & $\begin{array}{l}\text { Screening to check existing symptoms, CRC } \\
\text { symptoms more visible and detectable } \\
\text { reducing need for CRC screening }\end{array}$ & $\begin{array}{l}\text { Screening to check existing symptoms, } \\
\text { therefore unnecessary in the absence of } \\
\text { symptoms }\end{array}$ \\
\hline $\begin{array}{l}\text { Comorbidities and } \\
\text { previous colorectal } \\
\text { investigations }\end{array}$ & Comorbidities mentioned less frequently & $\begin{array}{l}\text { Felt less need for CRC screening because of } \\
\text { previous colorectal investigations }\end{array}$ & $\begin{array}{l}\text { Psychological and physical comorbidities made } \\
\text { less willing to screen }\end{array}$ \\
\hline \multicolumn{4}{|c|}{ Action-on-motivation challenges to colorectal screening } \\
\hline $\begin{array}{l}\text { Lack of health } \\
\text { professional } \\
\text { involvement }\end{array}$ & $\begin{array}{l}\text { Acknowledged CRC self-sampling was awkward, } \\
\text { but overcome }\end{array}$ & $\begin{array}{l}\text { Worried about completing FOBt incorrectly, } \\
\text { CRC burdensome and complicated, } \\
\text { disengagement from process possible for } \\
\text { breast and cervical but not CRC }\end{array}$ & $\begin{array}{l}\text { Worried about completing FOBt incorrectly, } \\
\text { CRC burdensome and complicated }\end{array}$ \\
\hline $\begin{array}{l}\text { Colorectal screening } \\
\text { requires planning }\end{array}$ & Detailed planning & Rarely described making plans to screen & Rarely described making plans to screen \\
\hline Comorbidities & Comorbidities mentioned less frequently & $\begin{array}{l}\text { Comorbidities impediments to CRC self- } \\
\text { completion }\end{array}$ & $\begin{array}{l}\text { Comorbidities impediments to CRC self- } \\
\text { completion and to a lesser extent breast and } \\
\text { cervical screening }\end{array}$ \\
\hline \multicolumn{4}{|c|}{ Prompts to colorectal screening } \\
\hline $\begin{array}{l}\text { Postponing and } \\
\text { forgetting }\end{array}$ & Described using prompts to avoid forgetting & $\begin{array}{l}\text { Lack of appointment time or deadline made } \\
\text { CRC more easily delayed or forgotten }\end{array}$ & $\begin{array}{l}\text { Lack of appointment time or deadline made } \\
\text { CRC more easily delayed or forgotten }\end{array}$ \\
\hline
\end{tabular}




\section{Treatment beliefs}

CRC-specific non-participants considered CRC treatment to be more severe than breast or cervical cancer treatment.

"I know that breast cancer caught early is really treatable. $\{\ldots\}$ I think cervical cancer's totally curable. $\{\ldots\}$ I don't really know that much about the bowel one. I mean, I know that bowel cancer's very, very serious. I mean, you can live without your breasts, you know, you can, you know, have a hysterectomy $\{. .$.$\} you cannae$ [cannot] really live without the bowels " (P134, 53 years, CRC-specific nonparticipant)

Similarly, for non-participants the most threatening aspect of cancer appeared to be its treatment. They questioned the effectiveness of cancer treatments to reduce mortality and expressed concern over side effects, such as hair loss, nausea, fatigue, and the quality of life that patients experienced during and after treatment. These respondents questioned whether they would accept treatment if they were diagnosed with cancer. Further, nonparticipants, mostly from those living in the least deprived areas, did not believe early detection could help them avoid cancer treatments that would reduce their quality of life.

"you just don't want to think of bowel cancer, and getting colostomies or whatever. Just the very thought. Sometimes I think I'd rather just not know and die, rather than be diagnosed with that and having a colostomy. $\{\ldots\}$ I would rather just die than go about like that, that's not living" (P45, 64 years, non-participant)

In contrast, the screening participants viewed cancer treatment more positively. 
"If you are unlucky enough and you lose the whole bowel and you have to have a colostomy bag then are you not better having that than dying?" (P58, 59 years, screening participant)

Beliefs about the value of CRC screening

CRC-specific non-participants questioned the value of CRC screening. These respondents doubted the efficacy of FOBt after having heard of others who had false negative FOBt results. They also believed that self-sampling reduced the credibility of CRC screening and completing the test in their own bathrooms seemed incongruent with the respondents' schemata for medical tests.

"if somebody [in health care team] had said ... you know, "Come along and sit on the toilet and we'll collect your poo," somehow it would have felt a little bit more detached, a little bit more kind of clinical $\{\ldots\}$ they'd probably have worked out some sort of system that they can do that more easily without needing plastic bags and God knows what else" (P121, 53 years, CRC-specific non-participant)

Disgust and embarrassment

The only test described as disgusting was FOBt. CRC-specific and non-participants spoke about disgust more often than screening participants. Participants' disgust related to FOBt being a self-completed test, the involvement of faeces and its association with bowel functions. In each group, participants described CRC screening to be embarrassing, with embarrassment relating to handling their faeces, storing the test kit and concern about other people (such as grandchildren) finding the FOBt kit, or postal workers having to handle the envelopes containing completed kits. Breast and cervical screening were perceived to be more acceptable and easier to discuss than CRC screening. 
"you would think getting your tits out or, you know, opening your legs for some speculum, you would feel as though both of those things ought to be more

CRC-specific non-participants reported talking about cancer screening less often and

Symptom beliefs symptoms.

specifically avoided talking about CRC screening, which respondents living in more deprived areas reported as off-limits for discussion. Respondents tended to describe talking about FOBt as immature, likening it to children laughing about "farts and smells" (P121, 53 years, CRCspecific non-participant). “you're told when you're young [laughs] not tae talk about stuff like that $\{\ldots\}$ except for when you're a boy when all bodily functions are, you know, extremely funny in your mind" (P134, 53 years, CRC-specific non-participant)

A theme among CRC-specific and non-participants was that they felt they would be better able to detect CRC symptoms, like indigestion or blood in their faeces than breast or cervical cancer symptoms. Similarly, non-participants also reported that they would 'know' if they had cancer making screening unnecessary, particularly in the absence of

“it [smear test] picks up any issues if you're not aware of issues $\{\ldots\}$ I think the bowel cancer one, you kind of know, most people know what the symptoms would be and therefore you assume that if you - since it's easy to see, that you're okay 

participant)

279 Screening participants believed that by the time cancer caused symptoms it would be advanced and less treatable. In contrast to CRC-specific and non-participants, screening participants thought they would have difficulty detecting CRC without FOBt.

Comorbidities and previous colorectal investigations

Some CRC-specific non-participants reported having had colorectal investigations and therefore felt less need for bowel screening. Non-participants also described how psychological and physical comorbidities made them less willing to complete screening. Physical comorbidities meant participants felt unable to cope with the prospect of additional investigations and/or treatment. Anxiety prevented some non-participants from deciding for or against cancer screening. A few reported depressive symptoms and thoughts of suicide; in this context cancer seemed to be an 'easier' (or, at least, a blameless) way to die-negating any perceived need for cancer screening.

\section{Action-on motivation challenges to CRC screening}

Lack of health professional involvement

CRC-specific non-participants and non-participants expressed worry about completing FOBt incorrectly without the support of a health professional. This set CRC screening apart from breast or cervical screening where health professionals conduct the tests. they're doing it right." (P150, 54 years, CRC-specific non-participant) 
To complete FOBt correctly, CRC-specific non-participants felt they needed to be fully engaged and 'pay attention'. In contrast, with breast and cervical screening they could disengage to some extent as the health professional completed these tests for them.

“When you go and get a cervical screen you don't have to do anything, you just turn up. For bowel screening, you've got to go that extra step. $\{. .$.$\} you've actually$ to make the effort to do it and collect the sample and seal it up and all whatever, and send it away." (P165, 54 years, CRC-specific non-participant)

CRC-specific non-participants described using disengagement during breast or cervical screening to cope with physical or psychological discomfort, but disengagement to overcome disgust or displeasure was not possible with self-completed CRC screening.

CRC-specific non-participants and non-participants reported CRC screening to be burdensome. Having to read instructions was considered to be a "hurdle" (P165, 54 years, CRC-specific non-participant) and FOBt to be complicated and effortful. Having to take three samples added to FOBt seeming burdensome. In contrast, screening participants rarely reported that FOBt was time consuming or complicated, but they agreed that taking faecal samples by themselves was awkward to do.

"If somebody was to $\{\ldots\}$ make it [FOBt] easy for me, I would have done it because I approve of the principle" (P166, 57 years, CRC-specific non-participant)

\section{CRC screening requires planning}

CRC-specific and non-participants rarely described making plans to do screening. In contrast, screening participants described detailed planning strategies to overcome practical barriers. They reported dealing with CRC screening invitations promptly and planned specific days to do the FOBt. Screening participants living in the least deprived areas also described routines 
for cleaning after FOBt completion and using gloves and wipes to make FOBt less disgusting

323 to them.

324 Impact of comorbidities

325 Illnesses and other conditions were an additional challenge to the self-completion of FOBt.

326 Non-participants most often reported unpredictable bowel movements, diarrhoea, IBS,

327 coeliac disease, multiple sclerosis and other health conditions as impediments to CRC

328 screening although such conditions were also mentioned by CRC-specific non-respondents. A

329 further two respondents with visual impairments reported abandoning half-completed FOBt

330 kits or waiting for a support worker to organise help with doing FOBt.

331 "I've got coeliacs, so, it's very, very seldom my bowel, my my my toilet is... what's

\section{Prompts to CRC screening}

336 Postponing and forgetting

337 Unlike breast and cervical screening, CRC screening is completed at home and does not require an appointed time. CRC-specific and non-participants reported that CRC screening could be more easily delayed or forgotten than cervical screening which only required them to make an appointment, and even more easily than breast screening where the appointment is pre-arranged. Some CRC-specific non-participants and nonparticipants living in the least deprived areas explained that they would put their FOBt invitation to one side and, as a result, forget about it. 
“if it's a bowel screening one, yep, put it somewhere and think 'Yes, l'll do that'

\section{DISCUSSION}

Our findings show that women who participated in breast and cervical but not CRC screening motivation into action.[16]

A key strength of our study was in achieving a sample of women whose screening histories were objectively established by linking three cancer screening programmes' data for the 
entire population of Glasgow, Scotland. To our knowledge, this has not previously been done. Among the CRC-specific non-participants and the non-participants the response rate to the invitations to be interviewed was extremely low (0.9-5.3\%) reflecting the difficulty of engaging all population groups in research, and the value of the data that has been obtained. The study has limitations; the SIMD measure used to assess socioeconomic deprivation was an areabased measure which offers a relatively blunt assessment and may offer one explanation for the limited number of socioeconomic deprivation differences noted in the analysis. The study focused on women due to the design, and so it is yet to be determined if the same specific CRC challenges apply to men. It is also noted that this study focused on increasing uptake of CRC and does not consider explicitly the role of informed choice principles. Some women make an informed choice not to engage in cancer screening which is entirely appropriate.[23] Our approach does not conflict with the principles of informed choice. For example providing more information reflecting advances in colorectal cancer treatment would increase knowledge.[24] However, interventions to address the identified motivational challenges would aim to improve knowledge and understanding and so support informed choice. The action-on-motivation targets would be aimed at supporting people who intend to screen to put their intentions into action and so would not compromise informed choice.

Understanding why CRC screening fails to achieve the uptake rates of breast and cervical has been explored in one previous self-report, survey study.[15] We are able to expand on the survey's results, as our findings explain that screening participants also dislike the selfcompleted FOBt, but manage these feelings; our findings show that medical reasons to for non-participation in CRC screening can include comorbidities that impede self-completed CRC screening, but also that women with previous colorectal investigations feel less need for CRC 
screening. Other studies have considered the relatively low uptake of CRC in isolation, and while they have identified similar barriers to the present study around, for example, fears about treatment, being asymptomatic, concerns about self-completion[8-11] etc., the present study adds a more nuanced understanding, which informs potential targets for future interventions to increase CRC screening uptake. While it is acknowledged that people are fearful of cancer treatment,[11, 25] the present study identified that women fear of treatments for CRC more than breast or cervical cancer, which may partly explain their reluctance to engage in CRC screening. Similarly, being asymptomatic is a commonly recognised barrier in the screening literature. $[8,26]$ Surveys have established that awareness of CRC symptoms is low,[27] but it was previously unknown that there may be a misunderstanding that colorectal symptoms are more easily self-detected than breast and cervical symptoms. Furthermore, the present study has illustrated the unique challenges of self-completion of CRC screening in the absence of a health professional, and the greater chance of procrastinating or forgetting the test in the absence of a specified appointment time. We note that similar barriers have been identified for Human Papillomavirus selfsampling for cervical screening.[28, 29]

We have identified potential targets for interventions to increase CRC screening uptake and drafted example policy recommendations (Table 4). For example, to reduce fear and misconceptions of CRC treatments, we recommend a concerted information campaign reflecting advances in CRC treatment and success stories.[30] To increase awareness that CRC screening is for people who are asymptomatic, we recommend a concerted information campaign to reiterate and reinforce existing messages that CRC screening is for the asymptomatic, and symptoms may only appear at an advanced stage. To reduce postponing 
415 and forgetting, we recommend providing a further reminder and potentially a suggested 416 deadline for kit return. It is important to note that Scotland replaced FOBt bowel screening 417 with Faecal Immunochemical Testing (FIT) in November 2017 and FIT will be introduced in 418 England and Wales in 2019. FIT requires only one faecal sample and, based on evidence from 419 pilot studies[31] and the initial months since its introduction in Scotland,[32] it is likely this 420 easier to complete test will increase uptake. Nonetheless, FIT alone is not sufficient to address 421 the other identified challenges to CRC screening uptake, and complementary interventions 422 are recommended. 


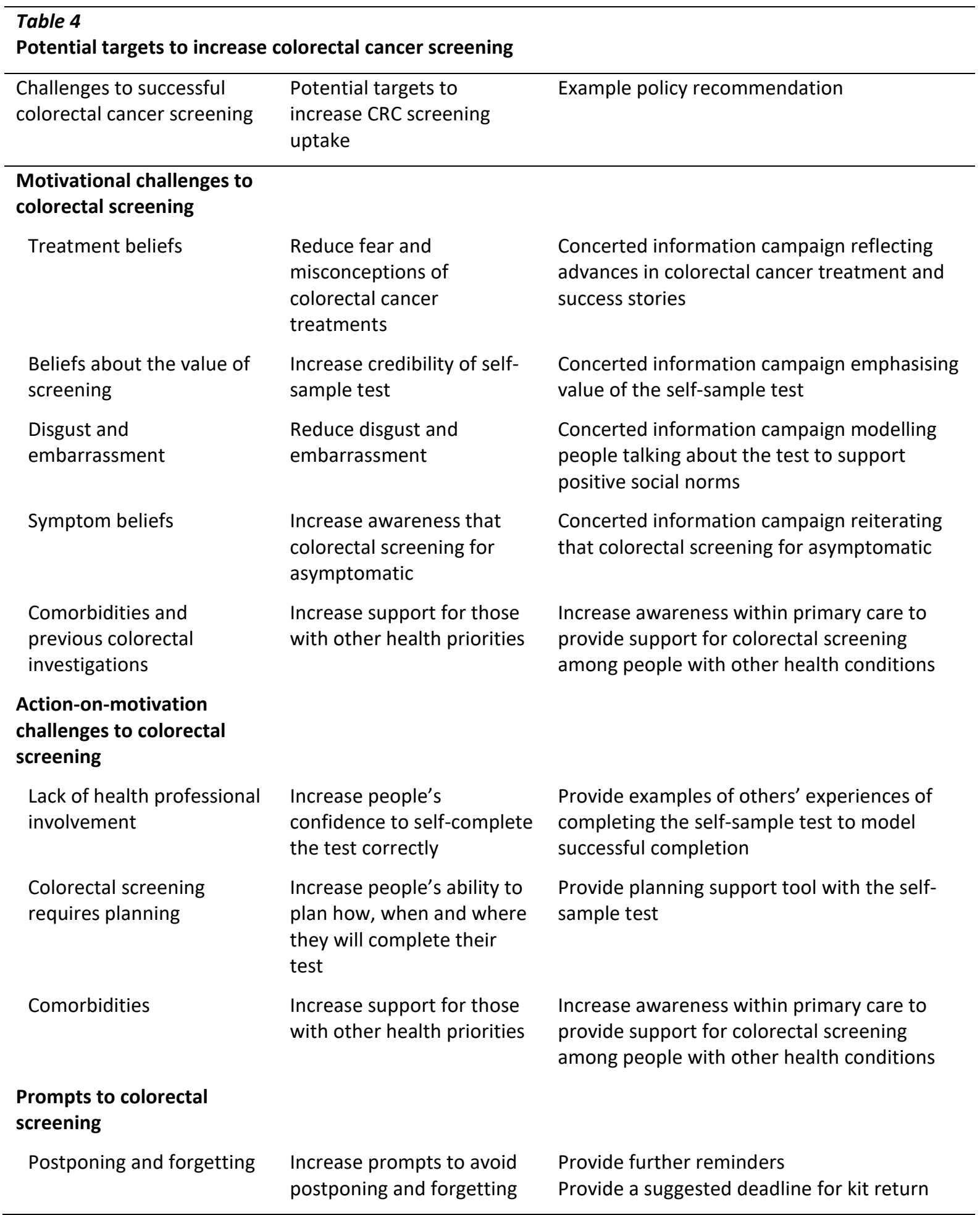


an intervention strategy increases uptake by affecting the specified targets.[22] This systematic approach is in line with current best practice guidance on the development of complex interventions, $[33,34]$ and will build on and expand existing knowledge of effective strategies to improve cancer screening uptake.[35]

\section{ADDITIONAL INFORMATION}

\section{Ethical approval and consent to participation}

Ethical approval was obtained from the NHS Health Research Authority (NRES Committee North West - Liverpool Central, REC reference: 4/NW/1300). Participants provided informed consent to take part in the study which was performed in accordance with the Declaration of Helsinki.

\section{Availability of data and material}

The datasets generated and/or analysed during the current study are available from the corresponding author on request.

\section{Conflict of Interest}

442 The authors declare no conflicts of interest.

Funding

This research was supported by a National Awareness and Early Diagnosis Initiative Grant (C9227/A17676) awarded to co-PIs KR and CMcC. The funder and sponsor had no involvement in the study design, data collection or analysis, or the writing and publication of the report.

447 All researchers involved in this study were independent of the funder and all co-authors had full access to all of the data (including statistical reports and tables) in the study and can take responsibility for the integrity of the data and the accuracy of the data analysis.

\section{Acknowledgements}


451 We gratefully acknowledge the Patient Involvement support from Ann Muir and Tom Haswell.

452 


\section{REFERENCES}

454

455

456

457

458

459

460

461

462

463

464

465

466

467

468

469

470

471

472

473

474

475

1. Ferlay J, Ervik M, Lam, F, et al. Cancer Today (powered by GLOBOCAN 2018). IARC CancerBase. Number: 15. Available from http://publications.iarc.fr/577 [Accessed $26^{\text {th }}$ March 2019].

2. Steele RJC, McClements PL, Libby G, et al. Results from the first three rounds of the Scottish demonstration pilot of FOBT screening for colorectal cancer. Gut 2009; 58(4): 530-35. Available from: doi:10.1136/gut.2008.162883.

3. Information Services Division. Scottish Cervical Screening Programme Statistics 2017/18. 2018. Available from: https://www.isdscotland.org/HealthTopics/Cancer/Publications/2018-09-04/2018-09-04-Cervical-Screening-Report.pdf [Accessed 26th March 2019].

4. Information Services Division. Scottish Breast Screening Programme Statistics 2015/16. 2017. Available from: https://www.isdscotland.org/HealthTopics/Cancer/Publications/2017-04-25/2017-04-25-SBSP-Cancer-Report.pdf. [Accessed 26th March 2019].

5. Information Services Division. Scottish Bowel Screening Programme Statistics. 2018. Available from: https://www.isdscotland.org/HealthTopics/Cancer/Publications/2018-08-07/2018-08-07-Bowel-Screening-PublicationReport.pdf? [Accessed 27th March 2019].

6. Centers for Disease Control and Prevention. Cancer screening-United States, 2010. Morbidity and Mortality Weekly Report 2012; 61(3): 41-5.

7. Australian Institute of Health and Welfare. National cancer screening programs participation data. 2019. Available from: https://www.aihw.gov.au/reports/cancer- 

March 2019].

8. Honein-AbouHaidar GN, Kastner M, Vuong V, et al. Systematic review and meta-study synthesis of qualitative studies evaluating facilitators and barriers to participation in colorectal cancer screening. Cancer Epidemiology and Prevention Biomarkers 2016; 25: 907-17.

9. Hall N, Rubin G, Dobson C, et al. Attitudes and beliefs of non-participants in a population-based screening programme for colorectal cancer. Health Expectations: An International Journal of Public Participation in Health Care and Health Policy 2013; 18(5): $1645-57$.

10. Jones RM, Woolf SH, Cunningham TD, et al. The relative importance of patientreported barriers to colorectal cancer screening. American journal of preventive medicine 2010; 38(5): 499-5.

11. Chapple A. Ziebland S, Hewitson P, et al. What affects the uptake of screening for bowel cancer using a faecal occult blood test (FOBt): A qualitative study. Social Science \& Medicine 2008; 66(12): 2425-35.

12. Wardle J, Robb K, Vernon S, et al. Screening for prevention and early diagnosis of cancer. American psychologist 2015; 70(2): 119-33. Available from: doi:10.1037/a0037357.

13. Young $B, L$ Bedford $L$, Kendrick $D$, et al. Factors influencing the decision to attend screening for cancer in the UK: a meta-ethnography of qualitative research. Journal of Public Health 2013; 40(2): 315-39. Available from: 10.1093/pubmed/fdx026

14. Mema SC, Yang $\mathrm{H}$, Vaska $\mathrm{M}$, et al. Integrated cancer screening performance indicators: a systematic review. PloS one 2016; 11(8): e0161187. 
15. Lo SH, Waller J, Wardle J, et al. Comparing barriers to colorectal cancer screening with barriers to breast and cervical screening: a population-based survey of screening-age women in Great Britain. Journal of Medical Screening 2013; 20(2): 73-9. Available from: doi:10.1177/0969141313492508.

16. Schwarzer R. Modeling health behavior change: How to predict and modify the adoption and maintenance of health behaviors. Applied Psychology 2008; 57(1): 129.

17. Dixon D, Johnston M. Health Behaviour Change Competency Framework: Competences to deliver interventions to change lifestyle behaviours that affect health. 2010. Available from: http://www.healthscotland.com/uploads/documents/4877Health_behaviour_change_competency_framework.pdf. [Accessed 26th March 2019].

18. Scottish Government. Introducing the Scottish Index of Multiple Deprivation 2016, Available from: http://www.gov.scot/Resource/0050/00504809.pdf [Accessed 26th March 2019].

19. McCaffery K, Wardle J, Nadel M, et al. Socioeconomic variation in participation in colorectal cancer screening. Journal of Medical Screening 2002; 9(3): 104-8.

20. Ritchie J, Spencer L, O'Connor W. Carrying out qualitative analysis. In: Ritchie J, Lewis J, editors. Qualitative research practice: A guide for social science students and researchers. London: SAGE Publications 2003:219-62.

21. Ziebland S, McPherson A. Making sense of qualitative data analysis: an introduction with illustrations from DIPEx (personal experiences of health and illness). Medical Education 2006; 40(5): 405-14. Available from: doi:10.1111/j.13652929.2006.02467.x. 

to Intervention. Annual Review of Psychology 2017; 68(1): 573-600.

23. Jepson RG, Hewison J, Thompson AG, Weller D. How should we measure informed choice? The case of cancer screening. Journal of medical ethics. 2005; 31(4): 192-6.

24. Ghanouni A, Renzi C, Meisel SF, Waller J. Common methods of measuring 'informed choice'in screening participation: challenges and future directions. Preventive medicine reports. 2016; 4: 601-7.

25. Robb KA, Simon AE, Miles A, et al. Public perceptions of cancer: a qualitative study of the balance of positive and negative beliefs BMJ open 2014; 4(7), e005434.

26. Power E, Miles A, Von Wagner C, et al. Uptake of colorectal cancer screening: system, provider and individual factors and strategies to improve participation. Future Oncology 2009; 5(9): 1371-88.

27. Power E, Simon A, Juszczyk D, Hiom S, Wardle J. Assessing awareness of colorectal cancer symptoms: measure development and results from a population survey in the UK. BMC cancer. 2011; 11(1): 366-75.

28. Forrest S, McCaffery K, Waller J, Desai M, Szarewski A, Cadman L, Wardle J. Attitudes to self-sampling for HPV among Indian, Pakistani, African-Caribbean and white British women in Manchester, UK. Journal of medical screening. 2004; 11(2): 85-8.

29. Nelson EJ, Maynard BR, Loux T, Fatla J, Gordon R, Arnold LD. The acceptability of selfsampled screening for HPV DNA: a systematic review and meta-analysis. Sex Transm Infect. 2017; 93(1): 56-61.

30. McGregor LM, von Wagner C, Vart G, et al. The impact of supplementary narrativebased information on colorectal cancer screening beliefs and intention. BMC cancer 2015; 15(1): 162-70. 
31. Digby J, McDonald PJ, Strachan JA et al. Use of a faecal immunochemical test narrows current gaps in uptake for sex, age and deprivation in a bowel cancer screening programme. Journal of Medical Screening 2013; 20(2), 80-5.

32. Information Services Division. Scottish Bowel Screening Programme Statistics. 2019. Summary.pdf? [Accessed 26th March 2019].

33. Craig $P$, Dieppe $P$, Macintyre $S$, et al. Developing and evaluating complex interventions: The new Medical Research Council Guidance. British Medical Journal 2008; 337: 97983.

34. Moore GF, Audrey S, Barker M, et al. Process evaluation of complex interventions: Medical Research Council guidance. British Medical Journal 2015; 350: h1258.

35. Duffy SW, Myles JP, Maroni R, et al. Rapid review of evaluation of interventions to improve participation in cancer screening services. Journal of medical screening 2017; 24(3): 127-45. 